\title{
THE DESIGN OF FLYING MACHINE
}

\author{
MUNWAR KHAN PATHAN ${ }^{1}$, K. DURGA RAO $^{2}$ \& SUDHAKAR UPPALAPATI ${ }^{3}$ \\ ${ }^{1}$ Student, Department of Aerospace Engineering, MarriLaxman Reddy Institute of Technology and Management, \\ Dundigal, Hyderabad, Telangana, India \\ ${ }^{2}$ Professor, Department of Mechanical Engineering, MarriLaxman Reddy Institute of Technology and Management, \\ Dundigal, Hyderabad, Telangana, India \\ ${ }^{3}$ Head of the Department, Department of Mechanical Engineering, MarriLaxman Reddy Institute of Technology and
} Management, Dundigal, Hyderabad, Telangana, India the basis of Bernoulli's equation and continuity equation. This design is to achieve a flight lighter than aircraft like hot air balloon works on a buoyancy principle. The main aim of thesis to design a machine structure along with a petrol engine which moves on the ground and make a take-off in the air safely with a human load and a glide in Ref[1-2]. After the assembly of the base structure along with the powered engine, propeller system and glide assumed to achieve a fly in the air with one man rider to a height of about 100 to 200 feet's safely. The glide design should be done appropriately otherwise the machine may not be lifted up due to the non-uniform velocity of air in Ref[3].

KEYWORDS: Engine, Design of Glider, Design of Aircraft Propeller, Air Flow, Thrust \& Designing of Transmission System
\end{abstract}

Received: Feb 27, 2019; Accepted: Mar 18, 2019; Published: Jun 13, 2019; Paper Id.: IJMPERDJUN2019184

\section{INTRODUCTION}

Flight is a natural phenomenon in the world. Birds do fly in the air by gliding with wings over long distances and by flapping their wings. Smoke, which contains tiny particles of dust, which can fly thousands of feet into the air. These both types of flying are possible because of physical science principles. Similarly, human-made aircraft depends on these principles to overcome the force of gravity and drag to achieve a fly.

Lighter than aircraft, like a hot air balloon, works on the principle of buoyancy. Like rafts float on water hot air balloon fly in air. Rafts float on water because its density is less than the water. Where as the density of water is constant but air density decreases with altitude. The balloon rises up, because the density of air inside the hot air balloon is less than the outside air at sea level. This will continue until the density of both inside and the outside air of hot air balloon and atmospheric air are equal. Smoke particles rise on a plume of hot air being generated by fire. When the air cools, the particles fell back to Earth.

A flying machine heavier than air is to design by a proper balance of four physical forces they are lift, drag, thrust, and weight. For flying, an aircraft's lift is must balance its weight means lift may be equal or higher than weight, and the thrust of aircraft must exceed its drag. An aircraft wings are used for lift of their airfoil structure and thrust by its engines. Drag is decreased by aircraft's smooth surface and the weight of aircraft is 
controlled by the material of its construction.

In order to fly an aircraft in air, the force created by the engines of the aircraft is must equals or exceeds force of gravity. This force is called lift.

$$
\mathrm{P}+\frac{1}{2} \rho V^{2}=\text { constant }
$$

\section{METHODOLOGY}

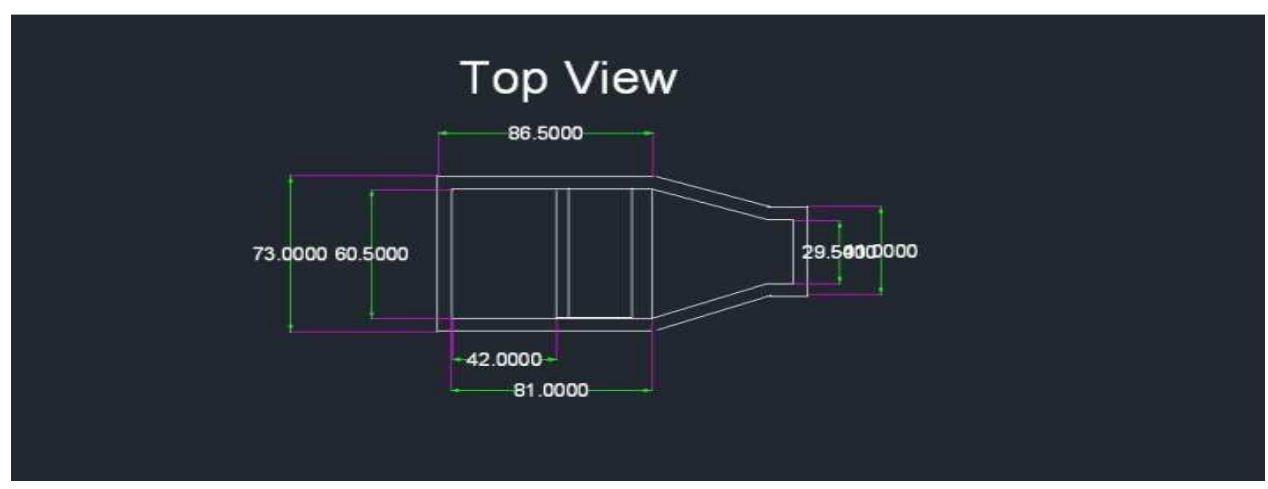

Figure 1: Top View of the Machine Structure

This structure is a $54 \times 20^{\prime \prime}$ length and this structure is fabricated over 3 wheels and this centre of the structure there is a seat for the pilot and in the back an engine base is fabricated on witch engine will be mounted. In the front side of the structure there is a steering to control both with hand and legs. And the back side is externally to height of 5 feet and thick vertical structure bent at about 800 angle. So that the hand of the glider from top will match to the center of gravity through the hand of the pilot in Ref[2].

This structure fabricated with light weight material aluminum and in some critical places MS is also used.

On the top of the structure there is a mechanism called glider.

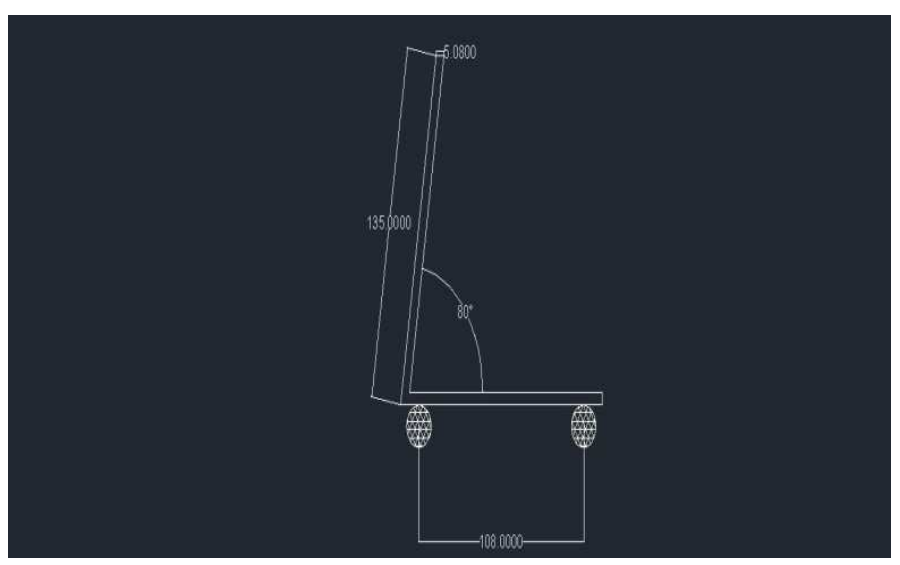

Figure 2: Side View of Machine Structure

Head where the glider and the navigation steering is fixed. There is a stay bar which connects the glider head to the front wheel steering head. This stay bar keeps the machine structure study and this will help the complete structure in a static position when the machine is lifted with the glider. 
The navigation steering can move the glider from 0-30 and 30-0 when the glider is in horizontal state. This 30 of the movement of glider can help the machine to lift it up in the air and down on the ground.

As per the capacity of the engine which we are using is to lift about $125(\mathrm{kgs})$ without any difficulty. So the design of the machine is made in such a way that the weight should not exceed more than $110(\mathrm{kgs})$.

As per the capacity of the engine the machine can move with a maximum speed of $60(\mathrm{kph})$ in the air.

Table 1: Properties of Materials used in Structure

\begin{tabular}{|c|c|c|c|c|c|c|c|c|c|c|c|c|c|}
\hline Name & $\begin{array}{l}\text { Density } \\
(\mathrm{kg} \mathrm{m}-3)\end{array}$ & $\begin{array}{l}\text { Melting } \\
\text { Point(k) }\end{array}$ & $\begin{array}{c}\text { Specific } \\
\text { Latent Heat } \\
\text { of } \\
\text { Fusion } \\
(\mathrm{j} / \mathrm{kg})\end{array}$ & $\begin{array}{c}\text { Specific } \\
\text { Heat } \\
\text { Capacity } \\
\text { (j kg-lk-l) }\end{array}$ & $\begin{array}{c}\text { Linear } \\
\text { Expansivity } \\
(\mathrm{k}-\mathrm{l})\end{array}$ & $\begin{array}{c}\text { Thermal } \\
\text { Conductivity } \\
\text { (Wm-lK-l) }\end{array}$ & $\begin{array}{c}\text { Electrical } \\
\text { Resistivity } \\
\quad(\Omega \mathrm{m})\end{array}$ & $\begin{array}{l}\text { Temperature } \\
\text { Coefficient of } \\
\text { Resistance } \\
(\mathrm{dp} / \mathrm{dT}) / \mathrm{K}-\mathrm{l}\end{array}$ & $\begin{array}{c}\text { Tensile } \\
\text { Strength } \\
(\mathbf{M P a})\end{array}$ & $\begin{array}{c}\text { Yield } \\
\text { Strength } \\
(\mathrm{MPa})\end{array}$ & $\begin{array}{c}\text { Elongation } \\
(\%)\end{array}$ & $\begin{array}{c}\text { Youngs } \\
\text { Modulus } \\
(\mathrm{GPa})\end{array}$ & $\begin{array}{c}\text { Poison's } \\
\text { Ratio }\end{array}$ \\
\hline & & & ${ }^{*} 104$ & & $* 10-6$ & & $* 10-8$ & $* 10-4$ & & & & & \\
\hline Aluminum & 2710 & 932 & 38 & 913 & 23 & 201 & 2.65 & 40 & 80 & 50 & 43 & 71 & 0.34 \\
\hline Iron & 7150 & 1500 & 10 & 500 & 11 & 75 & 10 & - & 100 & - & - & 110 & 0.27 \\
\hline
\end{tabular}

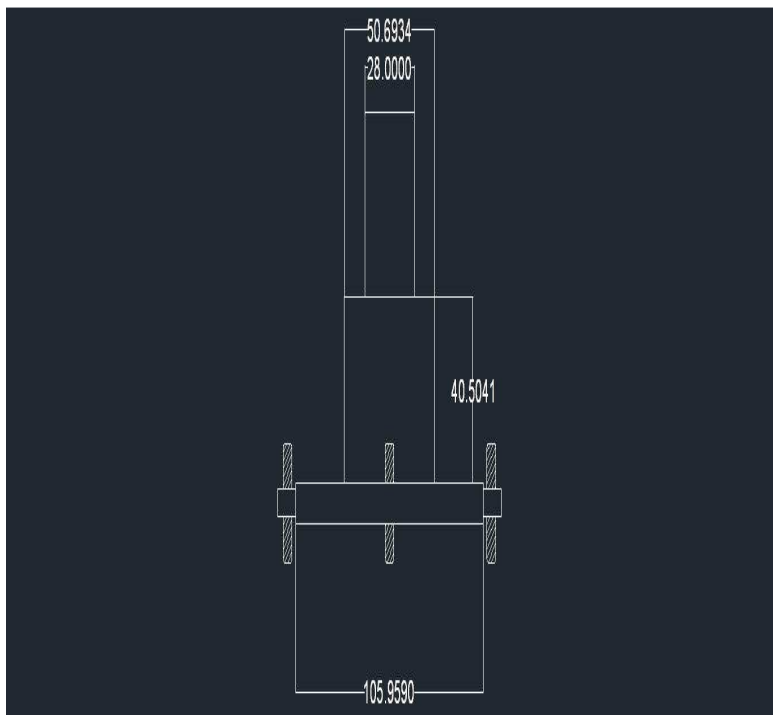

Figure 3: Front View of Base Wheels

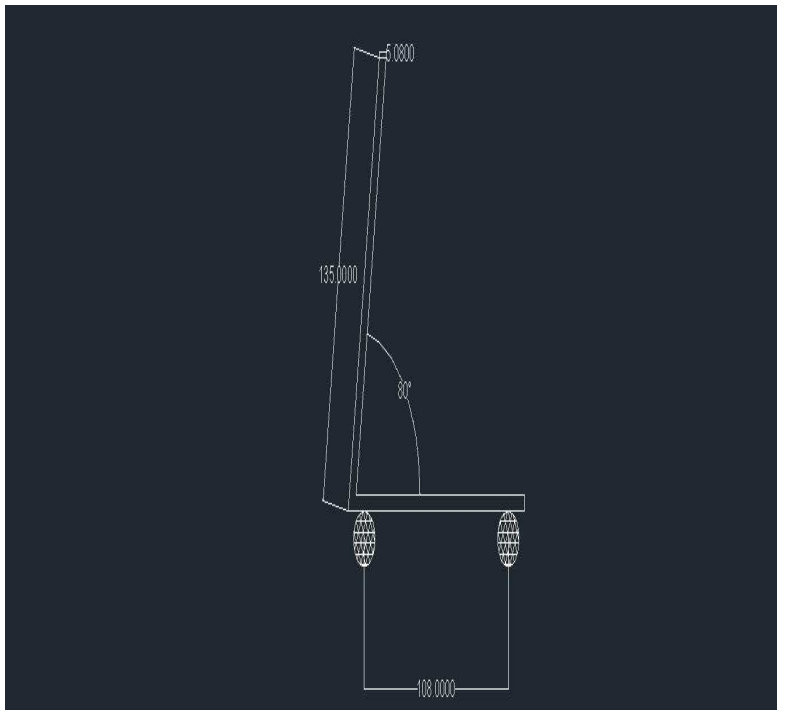

Figure 4: Side View of Base Wheels

In this structure three wheels are arranged, the back wheels where maintained at distance between each other and the front wheel is arranged at a distance of from back axel. Design of wheels was made in order to bear total setup of weighing $120 \mathrm{kgs}$. But the capacity of wheels is to bear $800 \mathrm{~kg}$ 's so we preferred these wheels in Ref[8].

Number of wheels used: 3

Wheel drum type : Alloy 


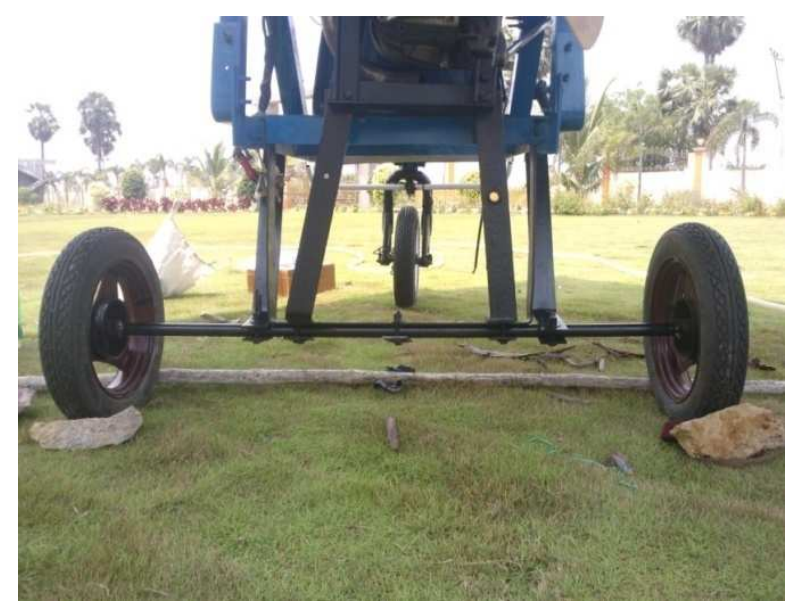

Figure 5: Wheel Axel

\section{Design of Wheel Axle}

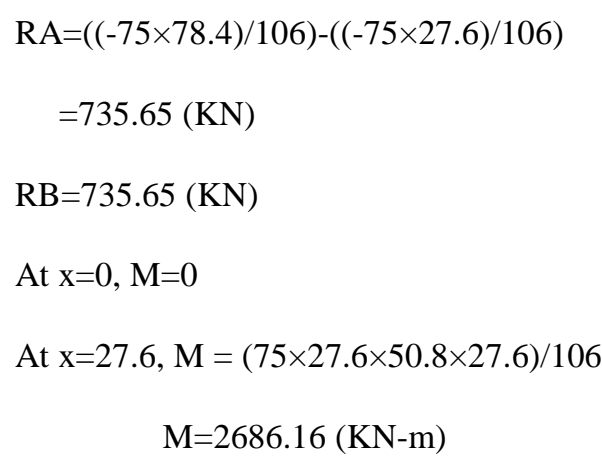

At $\mathrm{x}=0, \mathrm{~F}=150(\mathrm{KN})$

At $x=27.6, F=150-(75 \times 27.6)=18835.2(\mathrm{KN})$

At $x=78.4, F=150-(75 \times 27.6)-(75 \times 50.8)=-56211.3(\mathrm{KN})$

Table 2: Properties of Metals

\begin{tabular}{|c|c|c|c|c|c|c|c|c|}
\hline Material & \% Carbon & \multicolumn{3}{|c|}{ UTS (N/mm $\left.{ }^{2}\right)$} & \multicolumn{3}{|c|}{ Elastic Limit } & \%Elangation \\
\hline $\mathbf{T}$ & & Tension & Compression & Shear & $\mathbf{T}$ & $\mathrm{C}$ & $\mathbf{S}$ & \\
\hline Commercial & $0.10-25$ & 482 & 482 & 241 & 241 & 241 & 122.5 & 35 \\
\hline Cold rolled & & & & & & & & \\
\hline
\end{tabular}

Based upon the bending moment calculation the material is used to withstand the weight. So we have more than the requirement. The compression and tensile stresses are and bending moment. 


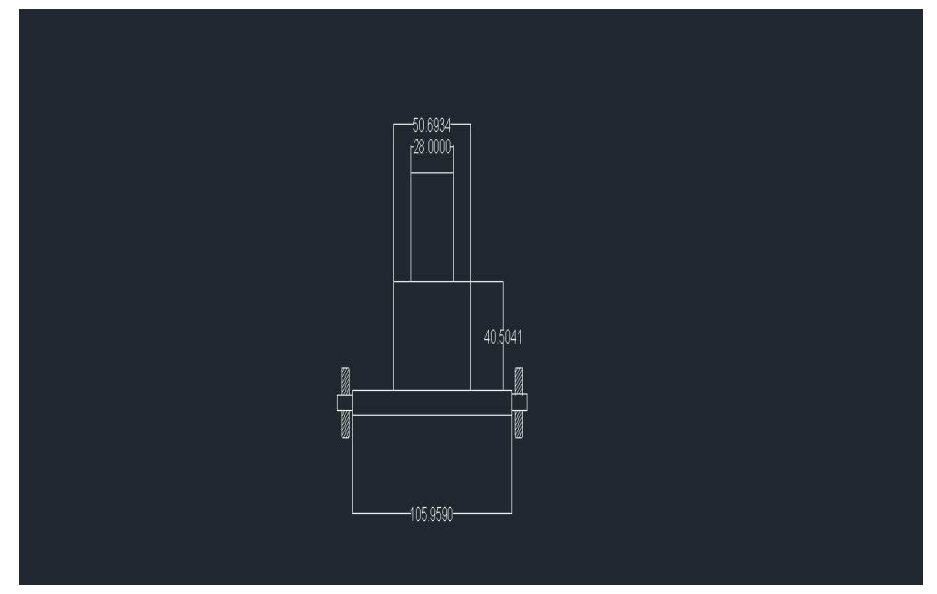

Figure 6: Design of Engine Base

The structure is made of mild steel which is used for weigh the weight of total engine. The engine is placed on the back wheels. On the back wheels we arrange the engine witch mount on the engine base. The height of the base is $40(\mathrm{~cm})$ and the width of the base is $50.69(\mathrm{~cm})$

For reducing the vibrations on the engine and structure we arrange the engine on the back of the structure. A proper engine installation and its position will give a number of advantages on unbalanced installations. The most important advantage is the longevity of components associated with the power plant. In so many cases high vibration occur due to improper installation of engine and it lead to premature of engine components.

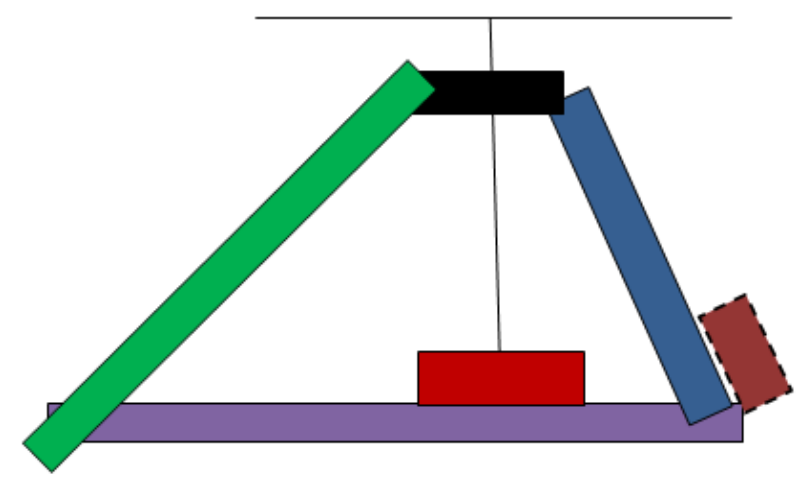

Figure 7: Balancing of Structure

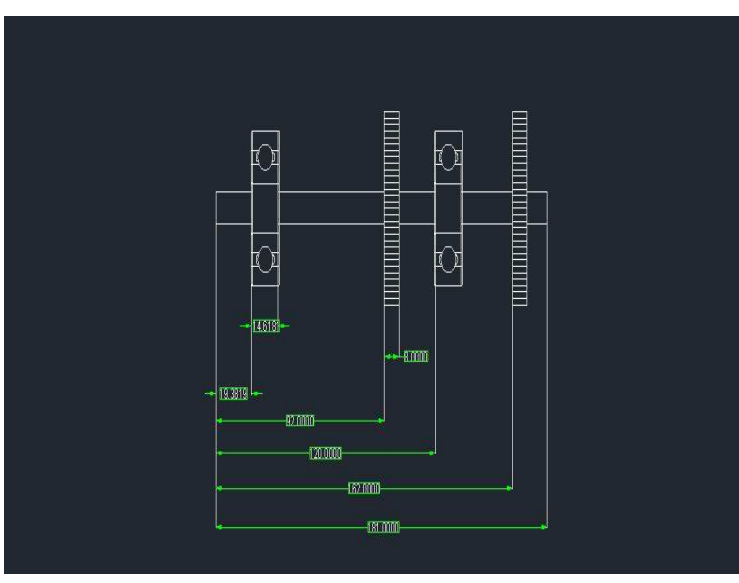

Figure 8: Design of Power Transmission-1

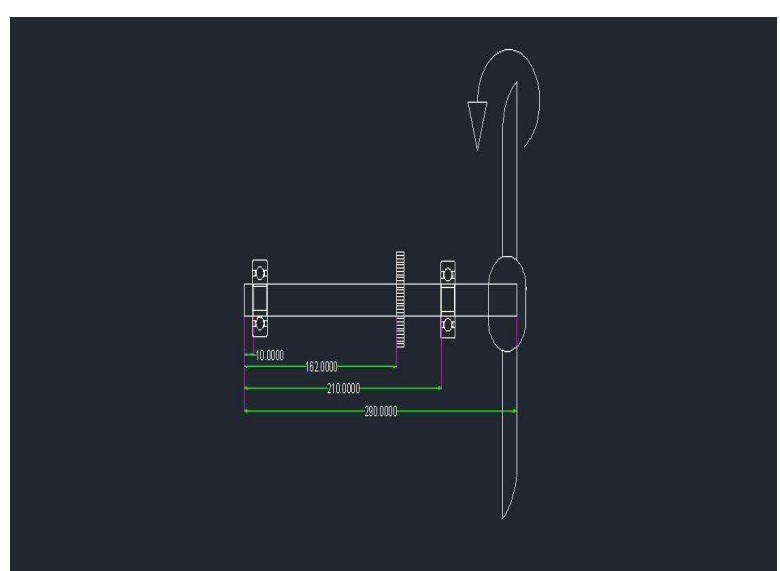

Figure 9: Design of Power Transmission-2 


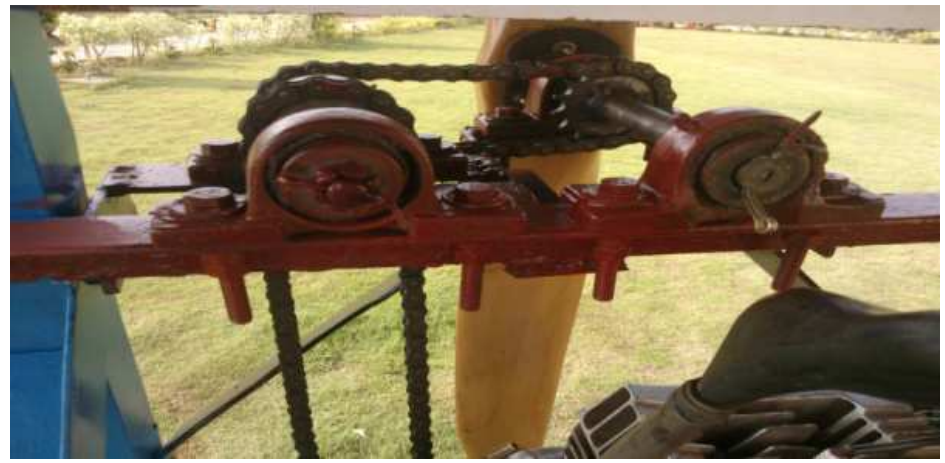

Figure 10: Design of Power Transmission-3

A structure is fabricated with four bearings to facilitate the sprocket shafts in which one sprocket receives the transmission from the engine through chine drive, another sprocket on the same shaft transforms the motion to the propeller shaft as shown in the fig. As per the speed of the engine the max rpm is $7500 \mathrm{rpm}$ and these bearing are suitably selected for the required rpm. The efficiency of a well-designed propeller in best operating regime is around $80 \%$. The efficiency of a propeller depends on angle of attack $(\alpha)$, which can be written as $\alpha=\Phi-\theta$, where $\theta$ and $\Phi$ are the helix angle which means the angle between the resultant relative velocity and the blade rotation direction and is the pitch angle of the blade respectively. Very little angles of helix and pitch gives a good performance against resistance but provide little thrust, while larger angles of them have the opposite effect. The best helix angle is when the blade is acting as a wing producing much more lift than drag in Ref[4].

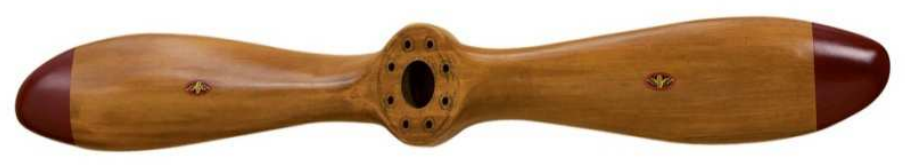

Figure 11: Wooden Propeller

The base is 10 (sq.ft.) to get a lift is 5 times of base area. But it has a glider height of 8 (ft) width of 16 (ft) and area is 64 (sq.ft.) the glider total weight is $10(\mathrm{kgs})$. Size of aluminum pipes are $1.5^{\prime \prime}$ and $2(\mathrm{~mm})$ thickness. The total weight comes approximately $10(\mathrm{kgs})$. As per the design the centre of gravity at the bottom of 32 " in the centre the glider should fix in the centre to the machine to the glider assembly. As per the required air foils over the wings the glider pipes has been fixed to the approximately camber of 6". This is required for the flow of air on and under the glider. In order for an aircraft to lift in to the air the force that created must be equals or exceeds the force gravity. Then, than force is called lift. This lift is created by the flow of air over an air foil as per the shape of air foil the air flows faster at the top then if the bottom. Because this of the shape of larger area of the top, and lesser area of the bottom. The fast flowing air decreases the surrounding pressure. The air pressure is greater below than the above. The same thing has been adopted in designing the glider. Where it is used the camber of 6". Here the Bernoulli's equation is applicable in Ref[6-7]. 


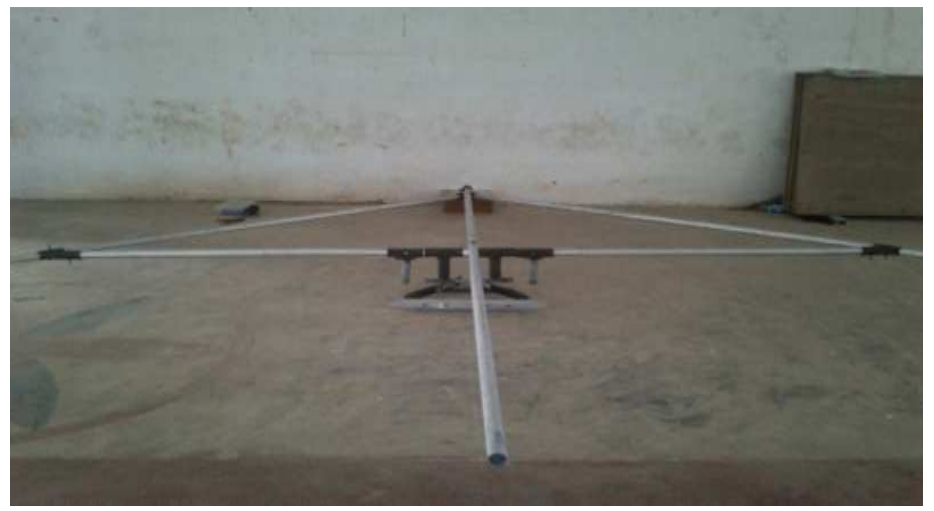

Figure 12: Design of Glider

Table 3: Properties of Glider Material

\begin{tabular}{|l|c|c|c|}
\hline \multicolumn{1}{|c|}{ Property } & Units & \multicolumn{2}{c|}{ Value } \\
\hline Material & Polyester & Medium & High Tenacity \\
\hline Specific Modulus & (N/tex) & & $700-800$ \\
\hline Specific Tenacity & (N/tex) & 36 & $70-80$ \\
\hline Density & (g-cm-3) & 1.39 & 1.39 \\
\hline Extension to break & $(\%)$ & 36 & $13-16$ \\
\hline Modulus & $(\mathrm{Gpa})$ & & $9-11$ \\
\hline Shrinkage @ $100^{\circ} \mathrm{C}$ & $(\%)$ & 4 & $1.5-6$ \\
\hline Tenacity & $(\mathrm{Gpa})$ & 0.5 & $0.9-1.1$ \\
\hline
\end{tabular}

Above table shows the properties of Glider Material in Ref [9]. This system is used to control the flying machine when it is in air. This system is mainly used during takeoff, landing and to turn in air. This structure consists of single pipe as shown in above fig the pipe is bended at radius of $0.5 \mathrm{inch}$ and the system is attached to the glider assembly. And due to its forward motion of navigation handle flight take offs and due to its backward motion flight lands and turn left and right by its respective motion. This system works on string arrangement in Ref [2].

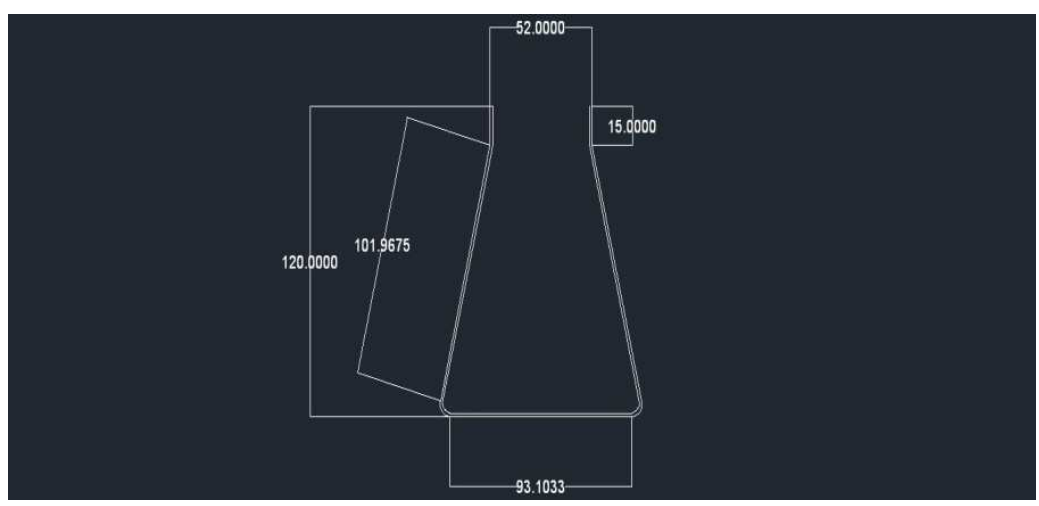

Figure 13: Design of Navigation Handling

\section{RESULTS AND DISCUSSIONS}

In maneuvering a glider, the pilot must adjust five undesired issues, undesired as in on the off chance that they didn't as of now exist, the designer would not plan them into the aircraft Amid preparing, the development of propensity examples to defeat these issues, is maybe the biggest single factor in figuring out how to fly. Achievement will be a lot simpler when the understudy comprehends the causes behind his vexations. 
The primary issue is adverse yaw, it is experienced when banking into or out of a turn adverse yaw is the drag on the wing which is raised, this is because of the expansion of approach by the brought down aileron (Remember that when you increment the angle of attack you bring down the airspeed, increment the lift and increment the induced drag). To roll into a left turn, for example, the pilot moves adhere to left side. This raises the left aileron depresses the right aileron. Since the down aileron produces more drag than the other, an unfortunate yawing to right side (against the bearing of the turn) happens, producing undesirable drag as the fuselage moves sideways through the air. To adjust this adverse yaw thus streamline the fuselage, the pilot applies left rudder with the left aileron. This activity is classified "coordinating stick and rudder", and the outcome is known as an appropriately planned turn when the yaw string and the slip-slide ball are focused.

Adverse yaw is mellow at low angle of attack however winds up extreme when the wing is almost slowed down. For instance, in a difficult maneuver which is near a quickened slow down, the use of full aileron to take off can slow down the low wingtip. The extreme delay this wing yaws the lightweight flyer into a plunge. In the event that the pilot presently makes the reasonable blunder of endeavoring to raise the lightweight plane's nose by pulling the stick considerably more distant back the outcome will be an abrupt turn. To recover from such an exorbitantly tough maneuver, the approach should initially be decreased by moving the stick forward, trailed by utilization of rudder. When you have a lowed approach use aileron/rudder to level the wings. An ordinary take off outcomes.

The plunging inclination is the second "I wish it wouldn't occur" in a turn. At the point when the lightweight plane is banked a portion of the wing's lift is exchanged from the undertaking of help to that of pulling the lightweight plane around the turn, as recently clarified. In outcome, the rate of sink increments, settling activity makes the lightweight flyer's nose drop, and the velocity increments. On the off chance that the pilot does not restrict this response of the lightweight flyer by moving the stick back, the velocity will before long balance out at a larger amount than once in the past. To keep up a similar speed in the turn as in straight flight the pilot must utilize the lift to keep the nose at such a situation seemingly within easy reach as to hold that speed. The more extreme the bank, the more back weight on the control stick is required.

The overbanking inclination is the third annoyance in turning. Having built up the desired edge of bank, the pilot finds that he needs to hold top aileron (against the point of bank) to shield the bank from steepening. In a lightweight plane this is valid in everything except the shallowest banks because of the long range and regularly little sweep of turn. The external wingtip moves quicker than the inward, so the external wing has more lift, making the bank steepen.

The fourth undesirable issue, a yaw against the course of a built up turn (not the antagonistic yaw brought about by aileron drag) shows up in light of the fact that the quicker moving external wing has more drag. Rudder toward the turn is expected to adjust the wing's yawing power, the sum being shown by the yaw string or slip-slide ball. On the off chance that these are focused the turn is accurately planned, despite the fact that the controls are crossed, which means rudder is connected on one side and aileron on the other. "Crossed controls" is an offensive sin in fueled flight. It ought to be noticed that the equivalent undesired impacts of a turn are in a fueled air ship, yet are most seen when in moderate flight or soak turns. The majority of these impacts are increasingly discernible in the sailplane in view of our long wings and slower speeds. Power pilots please note that a lightweight flyer is flown so the fuselage sneaks past the air with minimum drag, ball/yaw string in the middle, whatever position of the controls is required to achieve this end. The equivalent ought to be valid in a plane.

The fifth and last (thank heavens) issue of turning is the expansion in slowing down speed. As was clarified before, amid a turn the pilot applies back weight on the stick to increase the approach. Along these lines the lightweight 
plane is more like a slowed down point than in a dimension float at a similar speed. Another approach to take a gander at the circumstance is that the heap of radiating power is added to the heaviness of the lightweight flyer; this higher all out burden on the wing raises the slowing down speed. The thermalling pilot before long discovers that he needs to expand his velocity as he steepens his bank so as to keep from slowing down. It ought to be noticed that the expansion in slowing down speed is brought about by the expanded wing stacking as opposed to by the edge of bank as such. In the performance of aerobatic moves, for example, a wingover the bank might be vertical and the stick isn't brought back; there is no turning and no outward power, and the lightweight flyer's wing isn't slowed down despite the fact that the lightweight plane is momentarily hanging practically unmoving in a vertical bank.
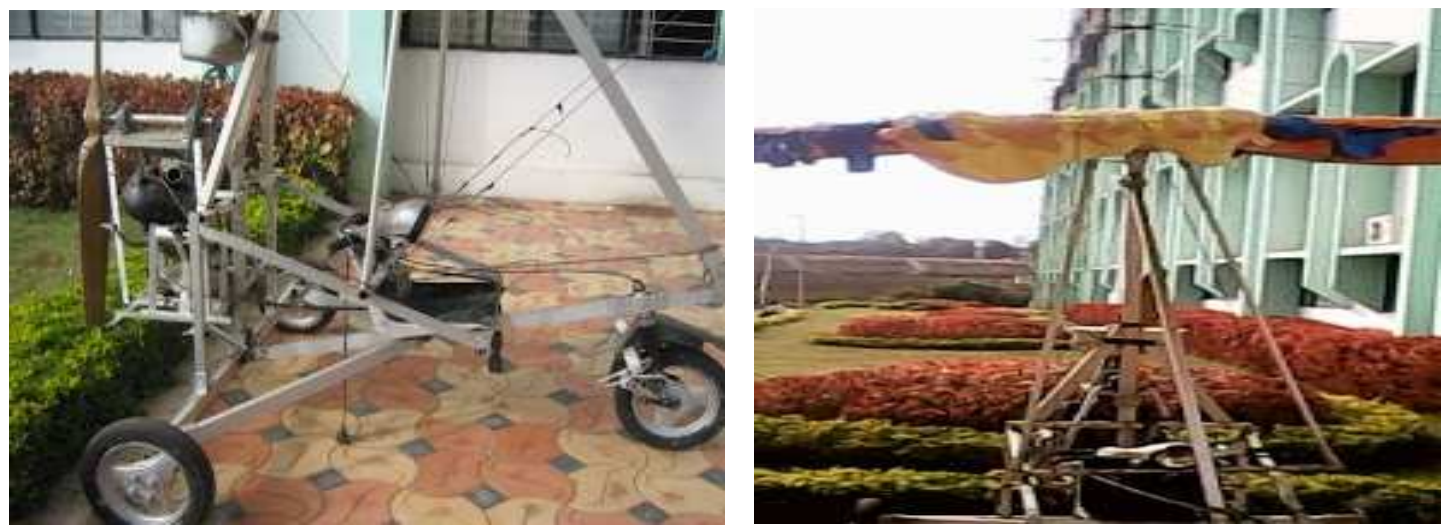

Figure 14: Final Assembly of Flying Machine

The following table gives an idea of the degree to which stalling speed increases with the angle of bank in a properly executed turn. The percentage increase is included so the reader can calculate actual values for any glider.

The stall speed is calculated by formula given below

$\mathrm{V}_{\mathrm{S}}=\sqrt{\frac{2 \mathrm{nW}}{\rho \mathrm{C}_{\mathrm{L} \text { max }} \mathrm{S}}}$

Where,

$\mathrm{V}_{\mathrm{S}}$ is Stall speed,

nis Load factor,

Wis weight,

$\rho$ is the air density,

$\mathrm{C}_{\mathrm{L}_{\max }}$ is the maximum lift co-efficient,

Sis the glider area.

Table 4: Results Obtained

\begin{tabular}{|c|c|c|c|c|}
\hline Angle of Bank & Load1 & $\begin{array}{c}\text { \% Increase in } \\
\text { Stall Speed }\end{array}$ & $\begin{array}{c}\text { Trainer Stalling } \\
\text { Speed }\end{array}$ & $\begin{array}{c}\text { High Performance } \\
\text { Stalling Speed }\end{array}$ \\
\hline $0^{\circ}$ & 1.0 & 0 & 31 & 46 \\
\hline $30^{\circ}$ & 1.18 & 8 & 33.5 & 50 \\
\hline $45^{\circ}$ & 1.4 & 18 & 36.5 & 54 \\
\hline $60^{\circ}$ & 2.0 & 40 & 43.5 & 64.5 \\
\hline
\end{tabular}




\begin{tabular}{|c|c|c|c|c|}
\hline \multicolumn{5}{|c|}{ Table 4: Contd., } \\
\hline $75^{\circ}$ & 4.0 & 100 & 62 & 92 \\
\hline $90^{\circ}$ & \multicolumn{4}{|c|}{ A "Properly Executed Turn" is impossible } \\
\hline
\end{tabular}

An attentive apprentice pilot (with instructor) making a full-hover turn at a height of not exactly a thousand feet while under solid and relentless breeze conditions, will be persuaded that lightweight plane turns are influenced by the breeze. A downwind way, even a lofty bank produces a turn of huge range over the earth and the lightweight flyer goes exceptionally quick. Turning in the upwind bearing, the sweep of the turn is exceptionally little and the speed is noticeably hindered. The student pilot realizes that breeze influences the manner in which the lightweight flyer turns since he can see the impact just by watching the ground. He feels that the airspeed marker must not be right, and that the instructor, who is stating the breeze doesn't influence the manner in which a lightweight flyer turns, basically doesn't trust the proof of his eyes.

Everything the fledgling sees is "totally so". It is the thing that he can't see, which is the movement of the package of air wherein he is flying that prompts his mistaken decision. He can't feel the solid breeze that is making his lightweight flyer act so flighty all contrasted with the normal steady rate turn.

A similarity may explain the circumstance. Consider a speedboat turning in a stream. The vessel, in making a steady rate turn, will before long keep running into its very own wake, and the captain had investigated the side and watched his way over the stream base, he would have seen the resultant of the roundabout movement of the pontoon and the straight movement of the waterway. It likely could never jump out at him that a vessel's turning capacity is distinctive in a stream than on the serene surface of a lake since he can see every one of the components that are included, not normal for our tenderfoot pilot.

When turning in a high wind the pilot rolls out no improvement in his utilization of the controls. Be that as it may, when he is worried about his track over the ground, as when in the rush hour gridlock design or on the cross-wind leg of a triangle flight, he should crab into the breeze enough to make up for the movement of the air.

\section{CONCLUSIONS}

This project is based on the following three equations. Bernoulli's theorem, Newton's third law and continuity equations. As per the three theorems, it has been proved that an object can move forward, by creating a sufficient thrust, without the drive mechanism with wheels.

It is also proved that there is a thrust against the drag as per the Newton's law of motion. By using a sufficient powered engine thrust has been created and drag has been developed and vehicle is moved forward. It is also proved that a weight can be lifted up with the air foil mechanism, which we called the name as glider.

Hence the glider will act as the air foil. Due to the sufficient drag is created and the full vehicle along with the pilot has been pulled forward and sufficient drag has been created. And the glider acted as a wing of a flight.

Thus with all the above we can proved that the above three theorems worked well and has been proved.

\section{ACKNOWLEDGEMENTS}

The authors would like to graciously thank Dr. K. V. Reddy, Principal, MarriLaxman Reddy Institute of Technology and Management for their continuous support during the course of work. 


\section{REFERENCES}

1. Lippisch, A. (1931). The Development, Design and Construction of Gliders and Sailplanes. The Journal of the Royal Aeronautical Society, 35(247), 531-578.

2. Alvarez, A., B. Garau, and A. Caiti, 2007: Combining networks of drifting profiling floats and gliders for adaptive sampling of the ocean. Extended Abstracts,2007 IEEE Int. Conf. on Robotics and Automation, Rome, Italy, IEEE, 157-162.

3. Jun Jiao, Bi-Feng Song, Yu-Gang Zhang, Yu-Bin Li. (2018) Optimal design and experiment of propellers for high altitude airship. Proceedings of the Institution of Mechanical Engineers, Part G: Journal of Aerospace Engineering 232:10, 18871902.

4. M. H. Rizk and W.-H. JOU, Propeller design by optimization, AIAA Journal, September, Vol. 24, No. 9: pp. 1554-1556.

5. M. Y. Smurov, A. V. Gubenko, International Journal of Applied Engineering Research ISSN 0973-4562 Volume 12, Number 3 (2017) pp. 394-401.

6. Adrian Emck and Colin Jackson Lasham, An Informal Survey of Flying Comfort of Glider Pilots: Some Observations Concerning Pilot Discomfort Generated by Glider Cockpits

7. Prasath, K. A., \& Johnson, R. D. J. Scrutiny of Machine Assignment in Various Intra-Cell Layout in Cellular Manufacturing using Automation Studios.

8. Guido de Matteis. "Dynamics of hang-gliders", Journal of Guidance, Control, and Dynamics, Vol. 14, No. 6 (1991), pp. 11451152.

9. R. K. Rajput, "Essentials of Strength of Materials", Text book for Mechanical Engineering.

10. http://textilefashionstudy.com/polyester-physical-and-chemical-properties-of-polyester 
